\title{
A História do desenvolvimento da teoria atômica: um percurso de Dalton a Bohr
}

The History of development the atom theory: the course of Dalton until Bohr

Ehrick Eduardo Martins MELZER ${ }^{1}$

Joanez Aparecida AIRES²

\section{Resumo}

Este artigo apresenta uma síntese da história do desenvolvimento das Teorias Atômicas no período anterior e posterior a construção do laboratório de Cavendish em 1874, localizado na Universidade de Cambridge na Inglaterra. Tem por objetivo mostrar que a construção dessas teorias contou com a colaboração de diferentes gerações de pesquisadores, o que caracteriza a ciência como uma construção humana paulatina e não linear. A história da ciência se constituiu como uma importante alternativa para o ensino da ciência. Neste recorte privilegiaram-se os pesquisadores que tiveram seus estudos ligados de alguma forma a este laboratório. Conclui-se argumentando sobre o quanto o conhecimento deste recorte pode contribuir para o entendimento de como a ciência é constituída, contribuindo, portanto, para a compreensão da ciência como produto de uma atividade humana e coletiva.

Palavras-Chave: ensino de química; história e filosofia da ciência; teoria atômica.

\section{Abstract}

This article summarizes the history of the development of the Atomic Theory in the period before and after the construction of the Cavendish Laboratory in 1874, located at the University of Cambridge in England. Aims to show that the construction of these theories with the collaboration of different generations of researchers, which characterizes science as a gradual and non-linear human construction. The history of science is constituted as an important alternative to the teaching of science. In this privileged to researchers who had cut his studies linked in some way to this lab. We conclude arguing about how much knowledge of this part can contribute to the understanding of how science is made, thus contributing to the understanding of science as a product of human activity and collective.

Keywords: chemistry teaching; history and philosophy of science; atomic theory.

\footnotetext{
${ }^{1}$ Universidade Federal do Paraná | ehrickmelzer@ufpr.br

${ }^{2}$ Universidade Federal do Paraná | joanez@ufpr.br
} 


\section{Introdução}

Este artigo apresenta uma retomada da história do átomo de John Dalton (1766- 1844) até Niels Bohr (1885-1962), contemplando as idas e vindas do desenvolvimento da Teoria Atômica durante o intervalo entre as proposições desses dois pesquisadores. Essa retomada se justifica na medida em que os livros didáticos, tanto da educação básica, quanto da educação superior, têm suprimido dados importantes para a compreensão de como os pesquisadores da Teoria Atômica chegaram a determinados modelos. A preocupação com os efeitos de tais lacunas sobre a compreensão de como a ciência é constituída tem estado presente em vários trabalhos da área de ensino de ciências (VIANA, 2000; LOBATO, 2007; LOPES, 2009), de História (KAZUMI, 2004) e, consequentemente, de História da Ciência (BELTRAN, SAITO e TRINDADE, 2011) e, especialmente daqueles que discorrem sobre livros didáticos (MORTIMER, 1988; LOPES, 1990; NIAZ, 2008; QUINTANILLA et al, 2008).

Niaz (2008) e Quintanilla et al (2008) analisaram livros didáticos de química e mostraram como eles trataram a questão da historicidade dos modelos atômicos. Ambos os trabalhos sinalizam que, na maioria dos livros analisados, tais modelos se encontram modificados e com recortes em suas histórias, os quais deixam de contemplar aspectos importantes sobre como se deu o processo de construção de cada modelo, bem como sobre quais fatores influenciaram sua construção. Em geral o que a maioria dos livros apresenta é uma história linear e descontextualizada desses modelos, sem problematizar quais razões levaram os cientistas à necessidade de propor outros modelos. Nesse sentido, buscando levantar aspectos do contexto onde foram produzidos os modelos atômicos ligados ao Laboratório de Cavendish, este trabalho tem por objetivo apresentar um recorte do percurso da história dos modelos atômicos desenvolvidos naquele laboratório, na medida em que são mais recorrentes nos livros didáticos de química brasileiros.

Para sistematizar este estudo, o artigo foi dividido em duas seções: a primeira corresponde ao período anterior à construção do Laboratório de Cavendish, localizado na Universidade de Cambrigde na Inglaterra, o qual, de acordo com Fitzpatrick e Whetham (1910), foi inaugurado em 1874. O segundo corresponde ao período posterior a sua construção. Esta divisão é enfatizada em função da fama mundial atingida por Thomson (LOPES, 2009), a qual fez do laboratório um centro de referência mundial para o desenvolvimento de estudos acerca da constituição da matéria.

A ordem de apresentação das propostas, portanto, está dividida nestas duas seções, objetivando demonstrar como cada modelo atômico foi desenvolvido e quais eram as preocupações dos pesquisadores na época. O período anterior à construção do Laboratório de Cavendish corresponde aos trabalhos de John Dalton (1766-1844). O período posterior corresponde aos trabalhos de J. J. Thomson (1856 - 1940), J. H. Jeans (1877 - 1946), H. Nagaoka (1865 - 1950), Lorde Rayleigh (1842 - 1919), G. A.Schott (1868 - 1937), E. Rutherford (1871 - 1937), J. W. Nicholson (1881 - 1955) e Niels Bohr (1885 - 1962).

\section{A abordagem HFC como catalisadora de propostas para o ensino de química}

Nas últimas décadas, a utilização da abordagem História e Filosofia da Ciência (HFC) vêm sendo amplamente defendida na área de ensino de ciências, por ser considerada 
capaz de contribuir para uma melhor compreensão sobre ciência, os aspectos que influenciam sua construção, bem como a própria atividade científica (MATHEWS, 1995; PEDUZZI, 2001; QUINTANILHA et al, 2008; MARQUES, 2010). Nesse sentido, Quintanilha et al (2008) argumentam que:

Existe um grande consenso entre os pesquisadores no campo das metaciências que a história da ciência permite identificar, caracterizar e compreender a influência dos contextos sociais, culturais, políticos e econômicos na construção do conhecimento científico, dimensões que em conjunto configuram uma determinada imagem da atividade científica, vinculadas com aspectos metodológicos, éticos e valorosos da própria ciência (QUINTANILLA et al, 2008, p. 98, tradução nossa).

Estes autores argumentam ainda que a HFC possibilita a compreensão de que a ciência não é produto da inspiração de um determinado pesquisador isolado e iluminado, mas resultado do trabalho intenso e gradativo de diversos indivíduos, algumas vezes em colaboração, outras vezes isoladamente.

Com base nessa compreensão, considera-se que contemplar a abordagem HFC no ensino de Ciências/Química deve corresponder a ações mais amplas do que a apresentação de fatos científicos isolados e trazê-los como uma espécie de "apêndice", muitas vezes no formato de anedotas, como comumente a história da ciência se faz presente nos livros didáticos e nas aulas. O desejável é que a abordagem HFC possibilite a compreensão de como esses fatos foram produzidos, quais indivíduos estiveram envolvidos nessa produção e como esses fatos estão interligados com os aspectos sociais, políticos e econômicos de determinada época.

Todavia, esses aspectos externalistas da ciência são pouco explorados nos livros didáticos, sendo mais valorizados os internalistas, conforme chamam a atenção Loguercio e Del Pino (2006):

No ensino usual da química é escassa a utilização de recursos históricos, estando ausentes em muitos livros de textos, e quando utilizados se referem a aspectos históricos "internos" da ciência (ênfase na visão internalista da ciência), como biografias, anedotas, inventos técnicos, ou de alguma área conceitual específica como modelos atômicos (LOGUERCIO e DEL PINO, 2006, p. 68).

Com muita freqüência, os aspectos internalistas da ciência são representados nos livros por meio de recortes da história, nos quais são comentadas apenas as datas de nascimento e morte de determinados cientistas e alguns de seus feitos. Essa apresentação fragmentada da história da ciência, muitas vezes veicula dados equivocados, os quais podem conduzir a visões distorcidas sobre a natureza da ciência. Ou seja, de acordo com Loguercio e Del Pino (2006), o mau uso de dados históricos e as perpetuações de alguns equívocos podem gerar imagens míticas e lendárias sobre a ciência e sobre os cientistas. Em relação aos cientistas, o educando pode construir visões estereotipadas, como se estes fossem seres que não fazem parte do mesmo mundo que o seu. Essa compreensão equivocada do que é ser um cientista é prejudicial tanto para a sua aprendizagem sobre ciência quanto para a sua formação como um futuro pesquisador. Considera-se, portanto, que propostas de ensino que contemplem HFC podem contribuir, humanizando os pesquisadores, mostrando-os como seres sociais que vivem em comunidades e participam delas. 
Todavia, há que se compreender também que a história de um acontecimento ou conceito químico dificilmente pode ser abordada completamente. Ou seja, frequentemente se faz necessário fazer recortes na história, no entanto, estes devem ser realizados sem prejuízos ao significado ou a compreensão do processo de construção de determinado conhecimento.

Fatos históricos, como o desenvolvimento da teoria atômica ou a construção do conceito de reação química, por exemplo, são histórias muito complexas, com centenas de pesquisadores que contribuíram para a sua construção, tornando inviável a sua comunicação de forma integral em sala de aula, seja na universidade (formação do professor) ou na escola (formação do estudante). No entanto, os recortes a estas histórias devem ser muito bem delineados, de modo a não distorcer a natureza da ciência e a visão epistemológica que se intenta apresentar ao educando.

A respeito desses cuidados, Quintanilha et al (2008) entendem que o professor que pretende utilizar a história da ciência, para ensinar química, deve estar bem fundamentado acerca da abordagem HFC, para que possa comunicar e adaptar didaticamente o projeto científico da melhor maneira possível, de forma a contribuir para uma formação mais completa e reflexiva dos educandos, desenvolvendo dessa forma, um ensino mais significativo. Outro ponto importante a destacar é que os livros didáticos de química, historicamente, tem apresentado uma história da ciência com enfoque histórico e filosófico de base empírico-indutivista. Desta forma, a compreensão da abordagem HFC possibilita o educador uma visão dessa história por diferentes enfoques epistemológicos, produzindo um retrato da ciência mais próximo da realidade.

A partir de tais reflexões, apresenta-se um dos recortes possíveis sobre a história do desenvolvimento da teoria atômica, fundamentada histórica e epistemologicamente em um determinado espaço social, como apresentado nas próximas seções deste artigo. Uma história do desenvolvimento da teoria atômica em Manchester na Inglaterra, anterior e posterior à construção do Laboratório Cavendish.

\title{
Período anterior à construção do laboratório de Cavendish
}

\author{
John Dalton (1766 - 1844)
}

Anteriormente a construção do Laboratório de Cavendish, John Dalton marcou o desenvolvimento da teoria atômica, apoiado, segundo Lobato (2007) e Viana (2000), por uma série de fatores de ordem profissional e de opções teóricas assumidas por Dalton. 0 Primeiro destes fatores refere-se ao fato de Dalton não ter, originalmente, uma formação química, mas sim matemática, que de acordo com Viana (2000), pode ter influenciado por uma perspectiva diferente de sua percepção dos fenômenos físicos e químicos. Outros fatores também podem ter sido importantes para a sua teoria, gerando uma série de interpretações sobre como Dalton chegou ao seu modelo atômico. Dentre estas podem ser citadas as influências dos trabalhos de Richter, a leitura do livro de Berthollet (1803-1804), algumas fontes também fazem referência aos trabalhos de análise dos compostos eteno e metano, aliado às leis das proporções múltiplas. Também, são citados os trabalhos e suas reflexões sobre as teorias de mistura gasosa, pelo estudo de pesos atômicos e o justificando com uma proposta mecanicista, com base em sua reflexão acerca das reações com Óxido Nitrogênio e das leis das proporções múltiplas. Tornou-se difícil uma ideia mais precisa 
sobre a elaboração do seu modelo, em função dos registros da sua produção ter sido, em grande parte, perdidos durante a Segunda Guerra Mundial.

Lobato (2007) argumenta que nenhuma destas interpretações apresentadas pelos historiadores da ciência pode ser desprezada, pois não se pode aferir o desenvolvimento teórico de Dalton a um único fator. O que é sugerido pelo autor é que todos esses trabalhos e acontecimentos fizeram parte de uma construção, culminando na proposta do átomo publicado em seu trabalho de 1810. Logo, o que se pode afirmar é que Dalton trabalhou sua teoria com base em múltiplas influências de físicos e químicos renomados de sua época, sendo que, de acordo com Viana (2000), a mais notável influência pode ter vindo da tradição newtoniana inglesa. O Principia (questão 26) e o Óptica (questão 31), de Isaac Newton, parecem também terem influenciado Dalton em suas leituras e interpretações dos fenômenos naturais e acerca da expansão e contração dos gases, determinando alguns aspectos de sua proposta de teoria atômica.

Assim, pode-se compreender que a teoria atômica foi construída a partir de uma série de trabalhos publicados por Dalton, todos eles com foco específico nas questões relacionadas aos gases e à composição da atmosfera. Ou seja, grande parte dos estudos pertencente à área de meteorologia. Nesse sentido, parece haver uma progressão e uma mudança na forma que Dalton encarava o átomo, de um corpuscularismo newtoniano, chegando a uma espécie de híbrido entre a teoria corpuscular de Newton e as leis de afinidade química, teorias muito estudadas na época, de acordo com os relatos apresentados por Viana (2000) e Lobato (2007). Lembrando que a construção do seu modelo começou em 1802 com a publicação da $1^{a}$ lei das misturas gasosas e terminou em 1810, com a publicação das mudanças teóricas ocorridas a partir de 1804, quando Dalton teve um encontro com T. Thomson e W. Henry, em que discutiram as bases da sua teoria atômica. De acordo com Viana (2000), o próprio Dalton em seu trabalho de 1810 reconhece o ano de 1804 como definidor de sua teoria atômica.

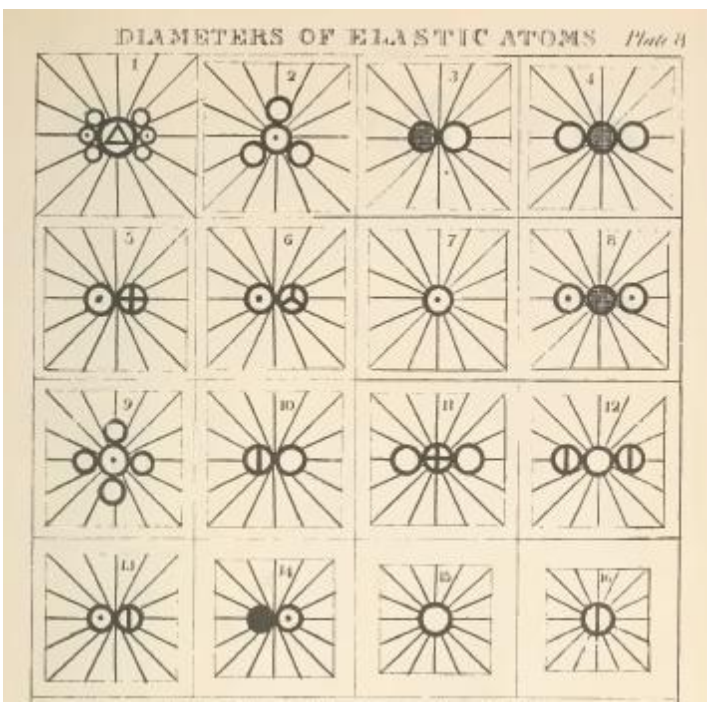

Figura 1: Representações de moléculas feitas por John Dalton em seu livro de 1810.

Com base nesta compreensão, pode-se afirmar que a teoria atômica de John Dalton, como publicada em sua forma final em 1810, passa por dois momentos distintos de construção: em um primeiro momento, Dalton baseou sua proposta em uma teoria ligada a seus estudos acerca da física proposta por Isaac Newton (na leitura do Principia e do Óptica), ancorada no corpuscularismo newtoniano. E um segundo momento, através de 
seus estudos sobre misturas gasosas (1802 e 1805), com todas as discussões e críticas feitas pelos seus contemporâneos que o fizeram analisar e conceber uma união entre a proposta Newtoniana de partícula com as propostas de afinidade química, ambas apresentadas em sua época. Para sanar equívocos e más interpretações do calórico, Dalton publicou o artigo "on heat" em 23 de maio de 1806, onde descreveu sua proposta para o calórico e como este era intimamente ligado a sua proposta atômica. Formulando as bases de seu átomo e o descrevendo como um corpúsculo esférico de tamanho variável que era envolvido por uma "atmosfera", denominada de calórico (heat), responsável pela atração e repulsão entre os elementos, medido e variável entre diferentes elementos químicos e quantificado através do valor de calor específico, como pode-se observar nas figuras 1 e 2.

Ao analisar a figura 1, pode-se observar que Dalton tinha uma preocupação: mostrar que todo o átomo é formado por uma esfera corpuscular maciça e, além disso, dotada de energia (calórico) que se manifesta pelos raios que foram representados por linhas, saindo do centro atômico. Outra preocupação de Dalton foi retratar átomos gasosos, mostrando, graficamente, como seu modelo atômico dava conta de explicar estados de maior repulsão. Para Dalton, o estado gasoso acontecia quando a "atmosfera" de calórico atingia seu maior valor, como mostrado na figura 2:

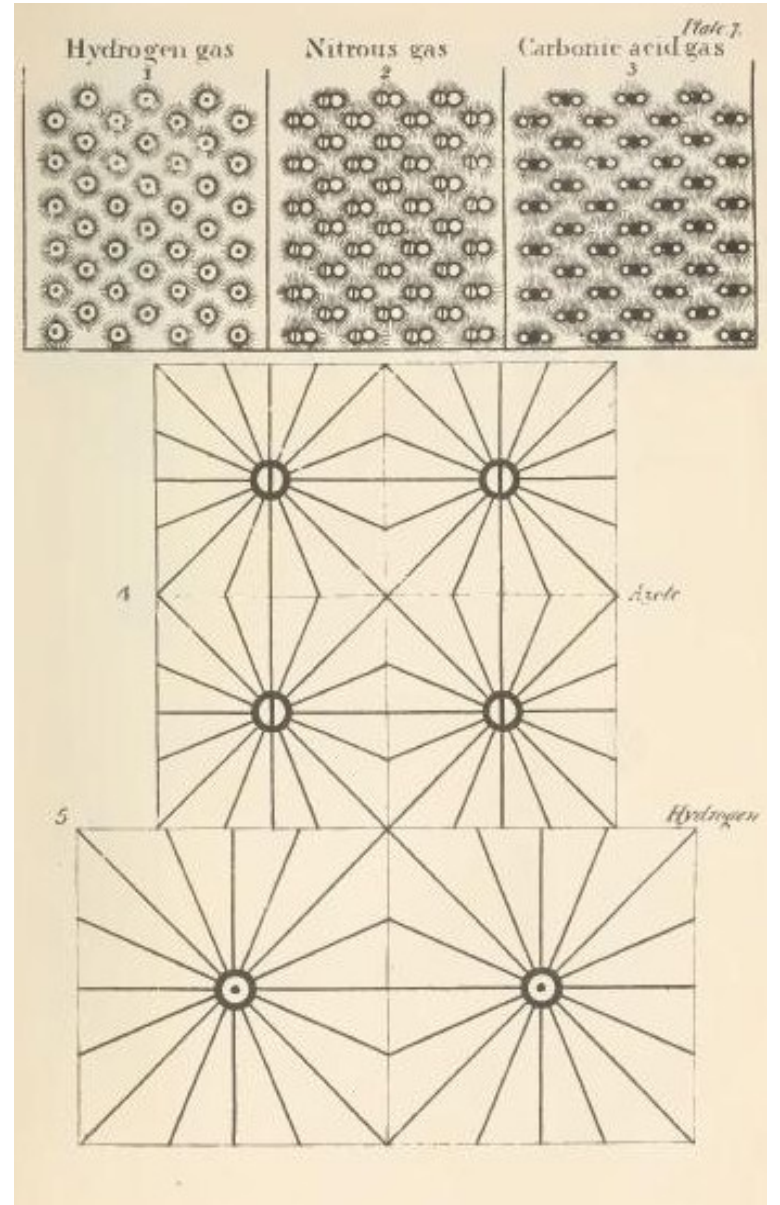

Figura 2: Representações de moléculas gasosas feitas por John Dalton em seu livro publicado em 1810.

Assim, pode-se compreender que este modelo dava conta, em sua época, de explicar os questionamentos que Dalton e outros pesquisadores tinham sobre o comportamento de gases, fenômenos meteorológicos, bem como a composição da atmosfera. Porém, essa 
proposta perdurou por vários anos até o seu modelo dar os primeiros sinais que chegara a um limite, onde eram necessários novos estudos para a estrutura atômica.

\section{Os trabalhos do século XIX e XX e a construção do Laboratório de Cavendish}

Antes de trazermos outros atores que participaram da construção da proposta atômica que culminou nas bases da quântica e da física moderna, se faz necessário trazer algumas leituras sobre o que foi desenvolvido no final do século XIX e início do século XX. Trabalhos estes que forneceram as bases e os dados empíricos necessários, bem como instrumentação para que a proposta atômica pudesse evoluir de um corpúsculo para algo mais complexo regido por leis mais complexas. Começaremos pelo final do século XIX, que é marcado por notórios estudos da física, química e astroquímica. Muitos destes estudos foram vitais para o estabelecimento da teoria atômica que conhecemos hoje. Destes estudos destacam-se os trabalhos sobre radioatividade, raios catódicos, elétrons, valência, espectroscopia, efeito Zeeman e, posteriormente, a bases da quântica.

Sobre estes trabalhos, Lopes (2009) apresenta uma relação dos autores divididos em áreas: na radioatividade com os trabalhos de E. Rutherford, F. Soddy, P. Curie, M. Curie, A. H. Becquerel, A. S. Eve, W. Bragg, H. Geiger, E. Marsden e H. Moseley. Nos raios X temos os trabalhos de $W$. Röntgen e todas as outras pesquisas que foram possibilitadas por essa descoberta. A eletricidade representada nos trabalhos de M. Faraday, G. J. Stony, J. J. Thomson e W. Crookes ${ }^{3}$. Na área de espectroscopia desde trabalhos assinados por $\mathrm{J}$. Melvin, J. Draper, D. Alter, A. Angströn, G. Stokes, B. Stewart, J. L. Foulcault, G. R. Kirchhoff, R. W. Bunsen, John Tyndall, J. Balmer, J. Evershed, J. Rydberg, H. Kaysen, Carl Runge, A. Fowler, W. Ritz, G. J. Stoney e Pieter Zeeman ${ }^{4}$. E na química com moléculas, ligação química e valência representada por S. Arrhenius, R. Abegg, G. Lewis e W. Kossel. Junto a outros trabalhos de Tabela Periódica (Mendeliev) que contribuíram de forma profunda para as propostas de Thomson, Nicholson e Bohr. Lembrando que toda essa produtividade teve uma estreita relação com as teorias atômicas, já que todos estudavam efeitos ocasionados pela constituição da matéria, desenvolvendo inúmeras pesquisas.

De acordo com Lopes (2009), Joseph Larmor já assinalava o átomo com uma proposta para explicar certos efeitos, demonstrando a necessidade que a comunidade naquela época tinha em explicar a sua modelagem e constituição.

Outro fator de impacto na concepção da teoria atômica está relacionado à tradição de Manchester, com seus estudos na área de física experimental. Este impulso é fortalecido com a criação e consolidação de grupos de pesquisa e associações, concentrando importantes físicos experimentais em Cambridge, obtendo seu ápice em 18745, a partir da inauguração do Laboratório de Cavendish, o qual foi considerado por vários físicos como o

\footnotetext{
${ }^{3}$ De acordo com Conn e Turner (1965) os trabalhos de Crookes com raios catódicos foram imprescindíveis para os estudos de Thomson e outros físicos de épocas posteriores.

${ }^{4} \mathrm{O}$ efeito Zeeman pode ser compreendido como "hipótese de que a luz emitida por um átomo tem sua origem no movimento vibratório dos elétrons no interior dos átomos" (CARUSO e OGURI, 2006, p.234).

5 Segundo Fitzpatrick e Whetham (1910) a construção do laboratório de Cavendish marca o ápice do investimento da Universidade em pesquisas de física experimental, culminou com toda a organização da sociedade de Física na Inglaterra.
} 
maior centro de estudos de constituição da matéria do mundo, tornando-se palco para grande parte dos avanços relacionados ao modelo atômico. Tal fama se deu muito em função de que Thomson, Rutherford, Nicholson, Schott, Jeans e Rayleigh que integravam diversas equipes e trabalhavam com pesquisas neste laboratório, bem como pela estreita ligação que Hantaro Nagaoka e Niels Bohr também tiveram com o mesmo. Pode-se afirmar, portanto, que este laboratório concentrou uma grande diversidade de pesquisadores, vindos de todo o continente europeu e de outros países, os quais buscavam aprimorar seus estudos e construir uma proposta coerente acerca da constituição da matéria e outras áreas afins.

A seguir são apresentados os pesquisadores que trabalharam com a constituição atômica após a construção do Laboratório de Cavendish e suas respectivas influências na constituição das teorias atômicas.

\section{Período posterior à construção do Laboratório de Cavendish}

$$
\text { Joseph John Thomson (1856 - 1940) }
$$

Thomson foi físico experimental. Esteve à frente do laboratório de Cavendish, sendo o grande responsável pela fama mundial deste, bem como pela migração de jovens cientistas que sonhavam em trabalhar em Cavendish sob sua orientação.

Fig. 1.
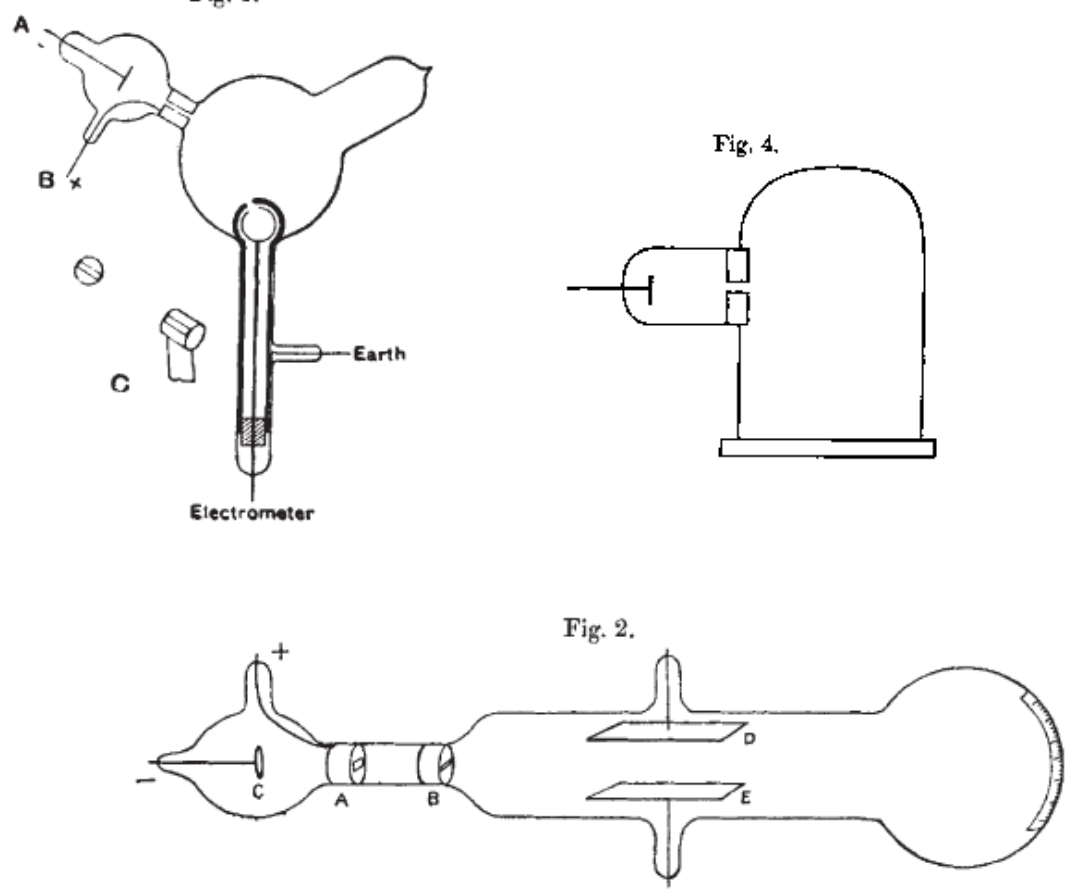

Figura 3: Esquemas experimentais testados por Thomson representados em seu artigo publicado em 1810.

Durante sua vida acadêmica debruçou-se sobre a questão da eletricidade e do átomo, mudando inúmeras vezes sua base teórica, que de acordo com Lopes (2009), é uma das mais notáveis características presentes nos estudos sobre a sua vida. Inicialmente, estudou o átomo vortex de Lorde Kelvin, aplicando-o a inúmeros problemas de combinações 
químicas, relacionando a questão da valência com o número de vórtices presentes no átomo. Posteriormente, influenciado pelas leituras de trabalhos de M. Faraday, Thomson elaborou um modelo atômico baseado em girostatos. Dessa forma, esse estudo sobre o modelo batizado de girostatos abriu caminhos para o cálculo da razão de carga negativa. Mas, foi em 1897, com a publicação de seu estudo sobre raios catódicos intitulado "On the cathode rays" que se abriu a possibilidade de uma profunda mudança em sua proposta atômica. Neste trabalho, Thomson utilizou vários arranjos experimentais para defender a visão newtoniana da física além de fazer o cálculo na relação de massa e carga para o elétron. Na figura 3 apresentam-se alguns esquemas de aparatos utilizado por Thomson.

No ano de 1903, na tentativa de compreender a distribuição dos elétrons com os cálculos de carga e massa do elétron, seus estudos culminaram em sua proposta atômica de 1904. O modelo apresentado por Thomson era formado por anéis coplanares de corpúsculos dentro de uma esfera de carga positiva e uniforme. As bases teóricas deste modelo são mais aprofundadas no livro "Theory of Matter" de 1907, no qual são apresentadas várias propostas e diversos estudos, o que se configurou na proposta atômica de Thomson.

Assim, pode-se perceber que há uma constante mudança ao longo da vida de J. J. Thomson no que diz respeito aos referenciais teóricos, mostrando a sua versatilidade de referencial em busca de novas perspectivas de pesquisa, bem como na junção de diferentes trabalhos para gerar teorias mais consistentes que respondiam a inúmeros problemas da época.

\section{James Hopwood Jeans (1877 - 1946)}

Em 1901, no artigo intitulado de "The Mechanism of Radiation", Jeans apresentou uma particular forma de interpretar os dados de Thomson, gerando o que foi denominado de átomo "ideal" de Jeans.

Com base em Conn e Turner (1965), na proposta de Jeans o átomo era formado por uma porção de cargas -e e uma porção de cargas $+e$, as quais estavam em um certo equilíbrio, permanecendo estáveis. Essas cargas estariam, mutuamente, se repelindo e se atraindo de acordo com a lei do inverso quadrado da distância, com base na análise de linhas espectrais de várias observações espectroscópicas. Este átomo "ideal" de Jeans, de certa forma, explicava com êxito o efeito Zeeman e descrevia as linhas dos espectros de Rydeberg.

Porém, ao que parece, este modelo era basicamente teórico, validado pelos dados da espectroscopia e que não ganhou muito destaque, pois três anos depois Thomson desenvolveu sua proposta atômica que deu conta desses problemas. O que pode ser observado dessa sua participação da história da Teoria Atômica é que Jeans trabalhou sob orientação de Thomson, o que o levou a definir sua proposta de átomo ideal seguindo a linha de raciocínio deste.

\section{Hantaro Nagaoka (1865 - 1950)}

Foi um físico japonês formado em Tókyo, no Japão, na época da restauração Meiji. Após terminar o mestrado, Nagaoka foi estudar na Europa onde conviveu com inúmeros pesquisadores notáveis da física. Durante suas viagens, Nagaoka fez uma série de contatos, inclusive com Rutherford, quando visitou o laboratório de Cavendish. E em 1904, publicou na revista Nature e depois na Philosophical Magazine a sua proposta de modelo atômico, 
baseada nos cálculos de Maxwell dos anéis de Saturno e adaptando-os para a escala atômica.

Em seu modelo, Nagaoka, de acordo com Conn e Turner (1965) e Lopes (2009), colocou um centro grande e carregado envolvido de anéis formados por corpúsculos que giravam com mesma velocidade ao seu redor. Com esta proposta era possível explicar vários fenômenos relacionados a diversas áreas de pesquisa. Porém, sua teoria encontrava um percalço com base na estabilidade de todo o sistema proposto, fazendo com que o tamanho e a energia da carga central fossem muito mais fortes que as cargas opostas que orbitavam ao redor do núcleo. Outro problema apresentado por este modelo era o da velocidade angular dos corpúsculos, que deveria ser muito alta, com valores que de acordo com a física clássica, eram difíceis de serem obtidos.

Este modelo foi fortemente combatido por Schott, que enviou cartas a Nagaoka, apresentando as fragilidades da sua proposta, estabelecendo assim um debate teórico entre os dois pesquisadores. Schott discordava dos cálculos de Nagaoka e também dos valores de carga central e de velocidade angular dos corpúsculos ao redor no anel, travando um longo debate sobre a validade do modelo saturniano. Posteriormente, Nagaoka desistiu de sua proposta e se dedicou a outras áreas de pesquisa. Em carta enviada a Neils Bohr, Nagaoka demonstrou sua felicidade e satisfação ao reparar a grande similaridade entre a sua proposta e do modelo atômico de camadas de Bohr a partir da proposta de Rutherford.

Lorde Rayleigh (1842 - 1919)

Foi físico experimental no Laboratório de Cavendish dedicando sua vida ao estudo do som. Ao longo de sua pesquisa sobre a constituição da matéria e eletricidade e, por influência dos seus contatos com Thomson, passou a fazer alguns estudos relativos à hipótese do fenômeno sonoro estar relacionado às propriedades atômicas.

Segundo Conn e Turner (1965), em 1906, Rayleigh sugeriu um modelo similar ao que Thomson apresentou em 1904, porém o número de elétrons em seu modelo teria uma variação para o infinito. Seu modelo também tinha uma semelhança com a proposta de Jeans, no entanto, diferia na forma de arranjo das diferentes cargas na estrutura atômica. Ou seja, Rayleigh optou por usar a mesma estrutura elucidada por Thomson, mas a variação de corpúsculos no interior da esfera positiva poderia chegar até o infinito. Rayleigh justificou essa possibilidade de acordo com a disposição das cargas e com a necessidade de haver a mesma quantidade de cargas positivas e negativas e de que a única diferença era que as cargas positivas estariam sem movimento de forma fluida, enquanto as negativas estariam com maior liberdade de movimento dentro da região delimitada pela esfera.

Esta proposta é uma tentativa de resposta para a definição do numero de corpúsculos negativos dentro do átomo, a qual Thomson não havia ainda conseguido chegar. Havia esta dificuldade porque ainda não se conhecia outras partículas e nem as relações de massa que seriam estudadas no átomo nuclear posteriormente. Logo, Rayleigh partindo desta problemática extrapolou o número de possibilidades a infinito, trazendo uma distribuição igualitária entre positivo e negativo.

\section{George Adolphus Schott (1868 - 1937)}

Schott em seu trabalho publicado na Phil Magazine, intitulado "On the Electron Theory of Matter and the Explanation of Fine Spectrum Lines and of Gravitation" explicou sua proposta do "elétron expandindo", publicado em junho de 1906. Em sua proposta, de acordo com Conn e Turner (1965), Schott levou em conta que todos os elétrons se movem 
em círculos com velocidades uniformes. Recordando que o problema de Jeans era que os elétrons estariam se movendo com uma velocidade muito alta e com um pequeno raio de giro, o que causaria um problema físico de movimentação. Para trazer uma possibilidade de elucidação e uma saída a esse dilema, Schott propôs que o elétron poderia se expandir e que ele internamente resistiria a essa expansão. Nesta compreensão, Schott levou em conta que o elétron é uma forma esférica que está sujeita a uma constante força (pressão) em toda a sua superfície. Ou seja, para Schott o elétron tinha a capacidade de se expandir para ocupar espaços dentro do átomo e, consequentemente, essa característica seria dominada pela pressão de todo o sistema.

Com base em suas investigações, Schott elaborou quatro postulados para o elétron no sistema atômico (CONN e TUNNER, 1965):

(1) O elétron se expande vagarosamente.

(2) Para satisfazer o princípio da conservação de energia, se faz necessário que haja um stress interno que resiste à expansão, a qual segundo a visão de Schott era um caso clássico de pressão hidrostática.

(3) Que esta força a que o elétron está sujeito é parte da natureza de um éter que rodeia o elétron.

(4) Assim a reação final no elétron era produto de uma pressão causada pela pressão do éter na superfície do elétron. Essa pressão não é exatamente balanceada com a taxa de expansão do elétron, porém, gravitam entre si como se o sistema se comportasse como um líquido.

São nestes postulados que Schott baseou seu modelo do elétron que expande, como uma tentativa de conciliar as observações de Rayleigh e Jeans sobre o átomo, numa forma de responder a inúmeras questões que surgiam naquela época e que não encontravam uma resposta satisfatória nas propostas de Thomson, Jeans e Rayleigh.

\section{Ernest Rutherford (1871 - 1937)}

Físico que dedicou sua vida ao estudo dos fenômenos radioativos e da física nuclear. Foi um dos precursores do átomo nuclear, junto com Nagaoka. Trabalhou com J. J. Thomson no laboratório de Cavendish e após se destacar em sua pesquisa, foi convidado pelo próprio Thomson a estudar raios $X$ e eletricidade. Posteriormente publicou com Thomson na Philosophical Magazine. Foi para o Canadá, por indicação de Thomson, para estudar com F. Soddy, onde ganhou um Nobel pelos trabalhos sobre radioatividade. Posteriormente, Rutherford retornou para Manchester e começou a influenciar toda uma geração de jovens físicos como Marsden, Darwin, Geiger, Bohr, Chadwick, dentre outros (LOPES, 2009).

Como relatam Conn e Turner (1965), Rutherford dedicou-se ao estudo das partículas radioativas e seu espalhamento mediante o bombardeamento destas em laminas metálicas, trabalho desenvolvido em conjunto de Geiger, Marsden e Royds. Neste trabalho, Geriger e Marsden fizeram testes de bombardeamento de partículas alfa em lâminas de inúmeros materiais, enquanto Royds trabalhou com o bombardeamento de partículas beta nos mesmos materiais, todos sob orientação de Rutherford. A opção pelo estudo de partículas alfa se deu devido aos melhores resultados obtidos em inúmeros testes.

Geiger e Marsden, juntos, estudaram e observaram os espalhamentos de partículas alfa em vários metais, o que os levou a publicarem um artigo na Royal Society. Após este trabalho, Geiger publicou outro artigo, explicando a preferência por usar somente o ouro nos experimentos, devido ao fato deste metal ser mais fácil de trabalhar e também por 
possuir os melhores coeficientes de espalhamento. Foram utilizados dois esquemas experimentais para o estudo do desvio de partículas radioativas em diferentes materiais, como mostra a figura 4:
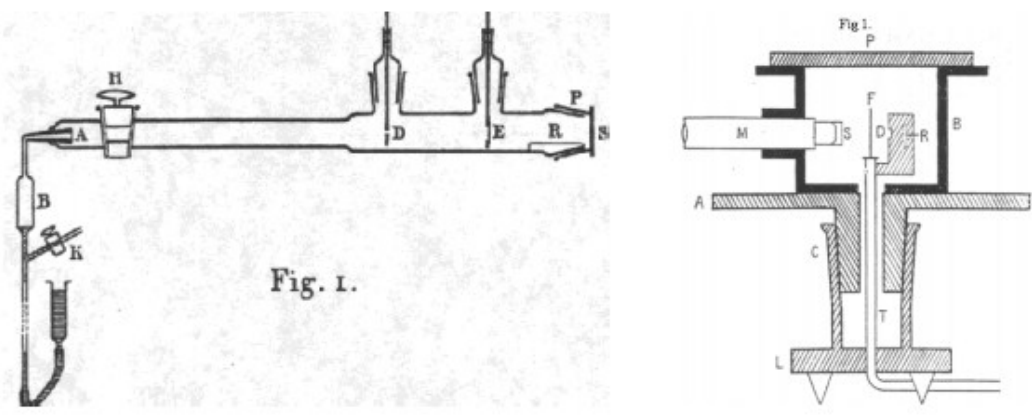

Figura 4: À esquerda esquema experimental apresentado por Geiger em artigo enviado no artigo de 1910. À direita esquema experimental apresentado em artigo escrito por Geiger e Marsden em 1913.

De posse dos resultados de Geiger colhidos a partir dos aparatos experimentais apresentados na figura 4, Rutherford tentou elucidar uma hipótese para o ocorrido, utilizando o modelo proposto por Thomson, que se mostrou inconsistente com os ângulos de deflexão das partículas alfa. Nesse sentido, Rutherford trabalhou levando em conta que o átomo teria uma região central e periférica.

Lopes (2009) argumentou que Rutherford nunca localizou as cargas no átomo, somente explicou que o sinal de cargas do núcleo e da região à sua volta teria que ser diferente para ocorrer atração. Logo, Rutherford defendia seu modelo como sendo um centro de carga concentrada, rodeado por uma distribuição esférica uniforme de cargas opostas de igual valor. Segundo Lopes (2009), este estudo não despertou interesse na comunidade, pois os pesquisadores da época estavam preocupados em elucidar os elétrons. Alguns anos após este trabalho é que é dada a devida atenção a esta questão, através dos estudos de Niels Bohr e de outros físicos.

\section{John William Nicholson (1881 - 1955)}

Astroquímico e estudioso de física de partículas também atuou no laboratório de Cavendish e posteriormente em Oxford, estudando os espectros da coroa solar. Propôs um modelo atômico baseado em seus estudos publicados em três artigos em 1911, os quais fizeram menção ao estudo de espectros da coroa solar.

Lopes (2009) e Conn e Tunner (1965) afirmaram que a proposta de Nicholson tinha relação com o seu estudo de movimentos de elétrons. Assim, Nicholson supôs um núcleo maciço e elétrons dispostos em órbitas, não tendo como referência a proposta de Rutherford e sim usando como base de suas investigações o modelo de Thomson e, possivelmente, o de Nagaoka.

Nicholson foi o primeiro a usar este modelo com sucesso para prever linhas espectrais de corpos celestes antes mesmo destas serem observadas (LOPES, 2009, p. 115).

Nicholson atribuiu as emissões do espectro a fenômenos de configuração eletrônica dos átomos. Para chegar a estes resultados utilizou ideias de Planck, as quais, segundo 
Lopes (2009), abriram caminho para outros estudos e para o desenvolvimento das bases da teoria quântica na Inglaterra. No seu modelo de átomo, Nicholson levou em conta quatro substâncias primordiais para a sua formação:

(1) Coronium: átomo com um anel com dois elétrons girando ao redor de um núcleo positivo.

(2) Hidrogênio ${ }^{245}$ : átomo com um centro e um anel com três elétrons girando ao seu redor.

(3) Nebulium: átomo contendo um único anel com quatro elétrons girando ao redor de um núcleo positivo.

(4) Protofluorine: átomo com um único anel com cinco elétrons girando ao redor de um núcleo positivo.

A união destas quatro substâncias desenvolveria todos os átomos dos elementos que atualmente conhecemos. Com esta proposta, Nicholson evitava os problemas que Schott apontou no modelo proposto por Nagaoka, do ponto de vista da estabilidade. E ainda usando sua proposta para calcular dois átomos hipotéticos contendo o Nebulium e Protoflorine, de acordo com Conn e Turner (1965). Posteriormente, como lembra Lopes (2009), este e outros trabalhos de Nicholson serviram de base para os cálculos do átomo de Bohr, mostrando sua importância no estabelecimento das bases de uma nova física e no desenvolvimento da teoria atômica.

Niels Bohr (1885 - 1962)

Niels Bohr desde o mestrado e do doutorado desenvolveu estudos teóricos sobre o comportamento do elétron, os quais não eram explicados quantitativamente. Desde 1911, época em que terminou seus estudos de doutorado, Bohr já estava convencido que era necessária uma ruptura da física clássica para uma nova física. No laboratório Cavendish, após ser recusado por Thomson, Bohr foi trabalhar com Rutherford nas pesquisas com partículas alfa, lidando com a variação de energia dessas partículas. Com os dados deste estudo, Bohr conseguiu desenvolver as bases do seu famoso artigo de 1913 (LOPES, 2009).

No ano de 1913, de acordo com Lopes (2009), Bohr publicou "sobre a constituição de átomos e moléculas", onde apresentou em três artigos as bases de sua teoria atômica, inspirada nos trabalhos anteriores de Rutherford. No primeiro artigo Bohr trouce os modelos de Thomson e Rutherford, fazendo várias ponderações sobre o cálculo, analisando como seu modelo era instável frente à dinâmica clássica.

Com esta trilogia de artigos, Bohr fez alusão a uma nova possibilidade, na qual a física clássica não daria conta de explicar certos fenômenos, necessitando de uma nova física. De acordo com Bohr (1963), quem sugeriu que Niels Bohr publicasse uma trilogia é Rutherford, depois de ler uma carta com uma cópia do artigo original, propondo uma simplificação de cálculos, ideias e conclusões, para se adequar a forma britânica de publicação. Em julho de 1913, época que ocorreu a publicação de sua trilogia, Bohr se encontrava em Copenhague e tinha uma estreita relação de amizade e comunicação com Rutherford, que lia todos os seus estratos de trabalho com o átomo, emitindo suas opiniões.

Segundo Lopes (2009), Bohr também teve contato com os trabalhos de Nicholson que - ajudaram a compreender a empregabilidade de cálculos, que foram à base de seu modelo atômico, mesmo seguindo um caminho completamente diferente do de Nicholson no uso da Constante de Planck (h). Com base no modelo proposto por Bohr, o átomo tem, como defendido por Rutherford, um núcleo central pequeno e positivo, que concentra toda a massa do átomo e, ao seu redor, há um número de elétrons realizando movimentos 
circulares. Na parte II de seu artigo, nos pressupostos gerais, Bohr deixou claro essa decisão tomada a partir do modelo de Rutherford para propor seu modelo:

Seguindo a teoria de Rutherford, supomos que os átomos dos elementos são formados por um núcleo carregado positivamente rodeado por um enxame de elétrons. No núcleo está concentrada a parte essencial da massa do átomo, sendo as suas dimensões lineares extremamente pequenas em comparação com as distâncias entre os elétrons que o rodeiam. (...) Postularemos que os elétrons estão dispostos em intervalos angulares iguais, rodando sobre anéis coaxiais em torno do núcleo. Com o fim de determinar a frequência e dimensões dos anéis empregaremos a hipótese principal do primeiro artigo, ou seja: que, no estado permanente de um átomo, o momento angular de cada elétron em torno do centro da sua órbita é igual ao valor universal $h / 2 \pi$, sendo $h$ a constante de Planck (BOHR, 1963, p. 133).

Através do trabalho de Bohr (1963), entende-se que os átomos possuem um núcleo denso e positivo que representa a maior parte do peso do átomo e que à sua volta há elétrons que descrevem órbitas circulares de acordo com o cálculo da constante de Planck (h). Estes dados são postulados, pois naquele momento a física ainda estava no paradigma clássico, o que necessitava uma mudança para um novo paradigma, o quântico. Com base nesta estrutura, Bohr estabeleceu que as emissões em séries de espectros fossem em decorrência da mudança e movimentos de elétrons de camadas mais externas para mais internas, seguindo um conjunto de regras postuladas ao final da trilogia de 1913:

Para se aplicarem os resultados obtidos por Planck é, portanto, necessário introduzir novas hipóteses sobre a emissão e absorção de radiação por um sistema atômico (BOHR, 1963, p. 195).

De acordo com Bohr (1963), estas cinco hipóteses tinham como base dois aspectos: o movimento e organização dos elétrons ao redor do núcleo, além da ocorrência da absorção e liberação de energia para gerar espectros luminosos dos elementos químicos. De acordo com as cartas de Bohr presentes no compêndio de 1963, a repercussão de sua teoria foi muito grande gerando questionamentos vindos de pesquisadores de todas as partes do mundo. Dentre estes se destaca A. Sommerfeld, que se mostrou mais participativo em debates teóricos, propondo cálculos para o modelo atômico de Bohr, bem como propondo que Bohr os usasse para problemas físicos já conhecidos como o do efeito Zeeman, dentre outros:

Agradeço-Ihe muito o envio do seu interessantíssimo trabalho, que eu já estudara no Philosophical Magazine. O problema de exprimir a constante de Rydberg-Ritz mediante a constante h de Planck desde há muito que me traz suspenso. Há alguns anos, falei nele a Debye. Conquanto eu seja ainda um pouco céptico perante os modelos atômicos em geral, há sem dúvida nos domínios daquela constante muito trabalho a fazer. Aliás, a estimativa numérica efetuada com o novo valor de $h=6,4 \times 10^{-27}$ é ainda melhor. Aplicou o seu modelo atômico ao efeito de Zeeman? Gostaria de tratar desse problema. Talvez possa em breve saber mais sobre os planos por intermédio de Rutherford, que espero ver em outubro (BOHR, 1963, p. 88). 
Assim, pode-se entender como Bohr, com sua trilogia de artigos, conduziu a uma significativa mudança na forma de pensar sobre a estrutura atômica, abrindo caminho a uma nova física que viria se instaurar anos mais tarde.

\section{Considerações Finais}

Neste trabalho apresentou-se um recorte da teoria atômica, que de acordo com Lopes (2009) é uma história rica e complexa com diversos grupos de pesquisadores analisando a constituição da matéria. Com base em Lopes (1990), Mortimer (1988), Niaz (2008) e Quintanilla et al (2008), os livros didáticos de química, geralmente, recortam esse episódio histórico, apresentando os modelos atômicos sem fazer referência ao percurso histórico da construção destes. Segundo Niaz (2008), a maioria dos livros didáticos ignora o fato de que o progresso da ciência envolve, entre outros aspectos, a competição entre diferentes grupos, bem como, conflitos entre estes, passando uma imagem de ciência linear, onde um modelo atômico simplesmente substitui o outro, quando na verdade estes competiram e foram postos à prova por toda uma comunidade de pesquisadores. Sendo assim, muitas vezes o livro didático apresenta somente o produto, e não o processo de construção da ciência. Ou seja, as idas e vindas da construção de um determinado modelo. Sendo assim, este trabalho pode vir a subsidiar a prática de professores que querem trazer esta compreensão dos processos de construção dos modelos atômicos, contrapondo-se à história simplificada e veiculada por muitos dos livros didáticos destinados ao ensino básico e ao ensino superior.

\section{Referências}

BELTRAN, Maria Helena Roxo, SAITO, Fumikazu, TRINDADE, Laís dos Santos Pinto. História da ciência - tópicos atuais. Editora livraria da física. 1ª Edição. 2011.

BOHR, Niels. Sobre a constituição de átomos e moléculas. In: Textos Fundamentais da Física Moderna: II Volume. Fundação Calouste Gulbenkian. Lisboa. 1963.

Briccia, V.: Carvalho, Ana Maria Pessoa de. Visões sobre a natureza da ciência construídas a partir do uso de um texto histórico na escola média. Revista Eletrónica Enseñanza de las Ciencias. 2011, V. 10, n. 1, p. 1-22.

CARUSO, F. OGURI, V. Física moderna: origens clássicas e fundamentos quânticos. Rio de Janeiro: Elsevier. 2006.

CONN, G. K. T. TURNER, H. D. The evolution of the nuclear atom. Londres: Iliffe Books. 1965.

FITZPARTRICK, T. C. WHETHAM, W. C. D. The building of the laboratory. In: A History of Cavendish Laboratory (1871 - 1910). Londres: LONGMANS, GREEN.1910.

KAZUMI, Munakata. Dois manuais de história para professores: histórias de sua produção. Educação e Pesquisa. V. 30, n. 3, p. 513- 529, 2004.

KÖHNLEIN, Janete F. Klein. PEDUZZI, Luiz O. Q. Uma discussão sobre a natureza da ciência no ensino médio: um exemplo com a teoria da relatividade restrita. Caderno Brasileiro de Ensino de Física. V. 22, n. 1, p. 26-70, 2005

LOBATO, César de Barros. Misturas e combinações químicas: estudos e explicações atômicas de John Dalton (1766 - 1844). Dissertação de Mestrado. PUC-SP. São Paulo. 2007. 
LOPES, Cesar Valmor Machado. Modelos atômicos no inicio do século XX: da física clássica a introdução a física quântica. Tese de Doutorado. PUC-SP. São Paulo. 2009.

LOPES, Alice R. Casimiro. Livros Didáticos: Obstáculos aos aprendizados da ciência química. Dissertação de Mestrado. Instituto de Estudos Avançados em Educação-FGV. 1990.

LOGUERCIO, Rochelle. DEL PINO, José Cláudio. Contribuições da história e filosofia das ciências para a construção do conhecimento científico em contextos de formação profissional da química. ACTASCIENTIAE. V. 8, n. 1, p. 67 - 77, jan/jul. 2006, Canoas.

MARQUES, Deividi Marcio. Dificuldades e possibilidades da utilização da história da ciência no ensino de química: um estudo de caso com professores em formação inicial. Tese de Doutorado. Bauru, 2010.

MATTHEWS, M. R. Historia, filosofia e ensino de ciências: a tendência atual de reaproximação. Caderno Catarinense de Ensino de Física. V. 12, n. 3, p. 164-214. 1995.13.

MORTIMER, Eduardo Fleury. O ensino de estrutura atômica e de ligação química na escola de $2^{\circ}$ grau: Comédia, tragédia ou comédia? Dissertação de Mestrado. Faculdade de Educação-UFMG. 1988.

NIAZ, Mansoor. From cathode rays to alpha particles to quantum of action: a rational reconstruction of structure of the atom and its implications for chemistry textbooks. Science Education. V. 82 (5), p. 527 - 552. 2008.

PEDUZZI, Luiz Orlando de Quadro. O uso da História da Ciência no ensino: consideraçôes e críticas. In: PIETROCOLA, Maurício. Ensino de Física: conteúdo, metodologia, e epistemologia numa concepção integradora. Editora da UFSC, cap.7, p.151-170, 2001.

QUINTANILLA, Mario. CUÉLLAR, Luigi. CAMACHO, Johana. La história del átomo en los libros de texto didáctica de una propuesta de innovación construida desde una visión naturalizada de la ciencia. Nova Época. V. 1 (2), p. 97 - 107, 2008.

VIANA, Hélio E. B. A Construção Atômica da Teoria de Dalton como Estudo de Caso - e algumas reflexões para o ensino de química. Dissertação de Mestrado. FE-USP. São Paulo. 2007. 